\title{
LA CARRERA ADMINISTRATIVA DE LOS FUNCIONARIOS PÚBLICOS FRENTE A LA LIBRE DESIGNACIÓN. ESPECIAL CONSIDERACIÓN DE LAS INTERVENCIONES EN LA PROPOSICIÓN DE LEY 1876 DEL DIPUTADO SR. PUIG Y LLAGOSTERA.
}

THE ADMINISTRATIVE CAREER OF PUBLIC OFFICIALS IN FRONT OF THE FREE DESIGNATION. THE PROPOSITION OF

LAW OF THE DEPUTY MR. PUIG Y LLAGOSTERA 1876.

EnRique Marcos Pascual

Secretario del Juzgado de Nájera con funciones de Letrado

Administración de Justicia

Profesor Asociado Universidad Burgos

Palabras claves: Poder legislativo, poder ejecutivo, Congreso de los Diputados, Administración, Gobierno.

Keywords: Legislative power, executive power, Congress of Deputies, Administration, Government.

Mots clés: Pouvoir législatif, pouvoir exécutif, Congrès des députés, administration, gouvernement.

Resumen: La carrera administrativa de los funcionarios públicos forma parte de la serie de reformas propias del régimen jurídico constitucional y el cambio de principios jurídicos que lo conforman, con la elaboración de la función pública subjetiva, frente a la deslavazada función pública objetiva configurada en el Antiguo régimen. Se predica que el acceso a la función pública se tiene que realizar en virtud de los principios de mérito, igualdad y capacidad. Por eso, 
históricamente, la organización de la carrera administrativa surge como alternativa a la designación de los funcionarios por libre designación del poder político. En el año 1876 se debate en el Congreso de los Diputados una Proposición de ley del Sr. Puig y Llagostera sobre la carrera administrativa. El Diputado defiende la aprobación de esta Proposición de ley en base a que hay que hacer de la función pública una profesión que él califica de "honrosa y honrada", que había que dignificarla. Que sea una profesión despolitizada, exenta por completo de las influencias y oscilaciones políticas y basados en unos criterios de mérito y capacidad en el ingreso y ascenso en la carrera administrativa.

Summary: The administrative career of public officials is part of the series of reforms of the constitutional legal regime and the change of legal principles that comprise it, with the elaboration of the subjective public function, as opposed to the deflated objective public function configured in the Old regime. It is predicated that access to the public function must be carried out by virtue of the principles of merit, equality and capacity. Therefore, historically, the organization of the administrative career arises as an alternative to the appointment of officials by free appointment of political power. In the year 1876 a proposal of law of Mr. Puig y Llagostera on the administrative career was debated in the Congress of Deputies. The Deputy defends the approval of this Proposition of law on the basis of which it is necessary to make of the public function a profession that he qualifies as «honorable and honored», which had to be dignified. That it be a depoliticized profession, completely exempt from political influences and oscillations and based on criteria of merit and capacity in the entry and promotion of the administrative career.

Recepción original: 7-2-2020

Aceptación original: 8-6-2020

\section{ABREVIATURAS}

CCAA

$\mathrm{RD}$

TREBEB

TEDH

TS
COMUNIDADES AUTÓNOMAS

Real Decreto

Texto refundido de la ley del Estatuto Básico del Empleado Público

Tribunal Europeo de Derechos humanos

Tribunal Supremo 
Sumario: I. Introducción. II. Evolución Histórica. III. Noción De Carrera Profesional. IV. La Promoción Interna: La Carrera Administrativa Del Funcionario Y La Carrera Vertical Del Funcionario. V. Conclusiones. VI. Referencias Bibliográficas.

\section{INTRODUCCIÓN}

La carrera administrativa se define como el conjunto ordenado de oportunidades de ascenso y expectativas de progreso profesional conforme a los principios de igualdad, mérito y capacidad.

Actualmente se regula, fundamentalmente, en el texto refundido de la ley del Estatuto Básico del Empleado Público, aprobado por Real Decreto legislativo 5/2015, de 30 de octubre (en adelante TRE$\mathrm{BEP})$, que reconoce, como derecho individual de los empleados públicos, el derecho al ascenso en la carrera profesional y a la promoción interna, según los principios constitucionales de igualdad, mérito y capacidad, mediante la implantación de sistemas objetivos y transparentes de evaluación (artículo 14 c). A su vez, su artículo 16 consagra el derecho a la promoción profesional de los funcionarios de carrera.

El actual modelo de carrera en la esfera de la función pública presenta un carácter abierto, de modo que cada Administración Pública, de acuerdo con sus propias competencias, podrá elegir el tipo y particularidades de carrera profesional que juzgue más apropiados para su concreta realidad. De hecho, lo establecido en el TREBEP sobre la carrera profesional causará efectos a partir de la entrada en vigor de las leyes de Función Pública que se dicten en desarrollo del Estatuto, conforme establece el número 1 de su disposición final cuarta.

En todo caso, conviene matizar que el derecho a la carrera no puede ser previsto como un derecho subjetivo absoluto, sino como un derecho a tomar parte en los procedimientos normativamente previstos para hacerlo efectivo: concursos para la provisión de puestos funcionariales, participación en cursos de formación, evaluación profesional individual, etc. En este sentido, el Estatuto Básico del Empleado Público propone un modelo de carrera directamente vinculado al ejercicio de las competencias profesionales, al desarrollo de las funciones propias del puesto de trabajo, desarrollo que se mide a través de la valoración del desempeño. La Administración, con el objetivo de la efectividad de su compromiso de servicio al interés general, puede y debe exigir al empleado público un adecuado 
nivel de diligencia en la verificación de su labor profesional, que somete a comprobación y valoración.

Por otro lado, es lógico el deseo de la Administración de que las responsabilidades sean asumidas por quienes presentan un mayor grado de capacitación para su óptima ejecución. De ahí, la necesidad de que sus empleados estén debidamente formados, en el bien entendido que una correcta capacitación -que necesariamente redunda en un mejor desarrollo de las tareas profesionales- propende, en última instancia, al reconocimiento en la carrera profesional y en el sistema de compensaciones conectado con la evaluación. El acceso a la función pública se tiene que realizar a través de los principios de mérito, igualdad y capacidad. Por eso, históricamente, la ordenación de la carrera administrativa surge como disyuntiva a que el poder ejecutivo nombre a los funcionarios mediante su libre designación.

\section{EVOLUCIÓN HISTÓRICA}

En la Constitución de 1812 de Cádiz, son muy escasas las referencias a los empleados públicos. Concretamente en el art. $171.5^{\mathrm{a}}$ recoge la atribución al rey de la facultad de proveer todos los empleos civiles. Se recogía incluso la venta de oficios públicos. En este periodo hay referencias a los denominados "cesantes", que eran los separados del servicio por razones políticas y que podían cobrar parte de sus haberes si eran rehabilitados, lo que se hizo en el Trienio Liberal mediante Real Decreto de 19 de abril de 1820.

Con la entrada del nuevo Ministro de Haciendo de Fernando VII, Luis López Ballesteros y Varela, que tomó posesión de su cargo el 3 de diciembre de 1823, y tomó una serie de medidas como el regular las reglas para el ingreso y ascenso de los funcionarios de Hacienda, estableciendo las nuevas bases del nuevo Estatuto de los Funcionarios Públicos ${ }^{1}$.

¡La Real Orden de 27 de enero de 1824, que tuvo como misión principal terminar con las cesantías en masa que convertían a la Función Pública en un "botín" de los monarcas y gobernantes. La Real Orden de 19 de agosto de 1825, que ha sido considerada como la primera regulación general del reclutamiento de los empleados públicos que se basaba, principalmente, en criterios de idoneidad.

1 Vid. RIVAS SANTIAGO: "Luis López Ballesteros: gran ministro de Fernando VII". Mediterráneo. Madrid 
Posteriormente, se dicta la Circular de 3 de mayo de 1825 que introduce, por primera vez, el concepto de idoneidad como el primer criterio para poder desempeñar un empleo público y, además, se crea la Junta de Jefes para valorar las distintas aptitudes de los funcionarios.

En el periodo absolutista, por Real Orden de 19 de junio de 1825 relativa al reclutamiento y categorías de la Secretaría de Estado y del Despacho de Hacienda. La Real Orden contemplaba 4 categorías de empleados públicos: meritorios, escribientes, oficiales y jefes.

En materia de incompatibilidades, a través de una Real Cédula, se establece que "los empleados de todos los ramos de la administración y resguardo de la Real Hacienda en actual ejercicio no puedan ser nombrados ni obtener destinos de ayuntamientos y demás cargos municipales, según se expresa" Por otra parte, se instaura la separación del servicio, a través de la Real Orden de 24 de septiembre de 1824, que establece que se "proceda a la separación absoluta del servicio a los flojos, indiferentes o poco celosos, y se imponga la pena de presidio por un tiempo proporcionado a todos los que incurran en un delito de complicidad en el fraude (...)."

El Real Decreto de 7 de febrero de 1827 que es la norma central de esta regulación, contiene disposiciones referidas a todos los ámbitos de la Función Pública, con la única particularidad de estar referida sólo a los funcionarios del Ministerio de Hacienda. No obstante, esto no le ha impedido ser considerado por algunos como el primer estatuto español de los funcionarios públicos².

Bajo el régimen del Estatuto Real de 1834, mediante un Real Decreto de 14 de diciembre de 1835, se pone de manifiesto depuraciones contra los constitucionalistas. El Estatuto Real sigue recogiendo que corresponde al rey y no al Consejo de Ministros, el nombramiento el nombramiento y destitución de los oficiales y empleados. Únicamente en las Constituciones de 1837 (arts. 47.9 y 66) y 1845 (arts 45.9 y 69) que incluyen la prerrogativa regia a lo que determinasen las leyes. Y por primera vez se recoge el acceso a la función pública mediante los requisitos de mérito y capacidad. López Ballesteros busca una mayor profesionalización de la Función pública, si bien no llega a ser un Estatuto de los funcionarios públicos, ya que solamente afectaba a los funcionarios del Ministerio de Hacienda.

2 NIETO GARCÍA,A.: "Estudios históricos sobre Administración y Derecho Administrativo”. INAP. Madrid, 1986.

(c) UNED. Revista de Derecho UNED, núm. 26, 2020 
Una de las primeras normas que va a regular la carrera administrativa de los empleados civiles del Estado es el Real Decreto de 18 de julio de 1852 aprobado por el Gobierno que presidía Bravo Murillo. En él se dividen las diferentes categorías en cinco:

— Jefes Superiores.

— Jefes de Administración.

— Jefes de Negociado.

— Oficiales y Aspirantes a Oficial.

Destacar que la figura de los subalternos, no tenían el carácter de empleados públicos para este Decreto. La intención de Bravo Murillo era fortalecer la Administración, siendo su lema "más administración y menos política" se podría hacer frente a la agitación existente en el país a causa de guerras y revoluciones ${ }^{3}$. El ingreso a la función pública se realizaba a la categoría de Aspirante, la selección se realizaba mediante un examen de ingreso o aptitud. El ingreso a las categorías de Oficial y Jefe de Negociado cuyo examen está formado por una prueba de oposición, la valoración de la antigüedad y la elección. El paso de un escalón a otro se establecía a través del turno de antigüedad y de elección. En cada Ministerio y Oficina Provincial hay unas Juntas de Jefes con atribuciones relativas a la calificación de los méritos, formación de escalafones y materias disciplinarias.

Con anterioridad a 1876 como señala García Martín ${ }^{4}$ siguiendo a Pérez- Prendes,

"Si bajo el sistema jurídico del ius commune, la flexibilidad institucional y el principio de delegación impedían la definición estatutaria- orgánica y funcional- de los empleados públicos, en la medida en la que se entienden como oficiales del rey a los que podía encargarse tareas diferentes en función de las coyunturas- tanto administrativas como judiciales-, bajo el constitucionalismo el ideal, que no empieza a definirse hasta la época isabelina (1852) - momento en el que aumenta el número de sus efectivos, será la de "acción administrativa", organizada en torno al concepto de función pública bajo las ideas de jerarquización, racionalización y selección."

3 PRO RUIZ , J.: "Bravo Murillo: Política de orden en la España Liberal". SÍNTESIS. Madrid, 2006.

4 MORÁN MARTÍN, J., GARCÍA MARTÍN, J., Historia de la Administración en España: Mutaciones, sentido y Rupturas, Editorial Universitas S.A. Madrid, 2018, pág. 422. 
Una importante reforma en cuanto a la carrera funcionarial es la conocida como ley de funcionarios, aprobado por Bravo Murillo por Decreto de 18 de junio de 1852. En dicha ley se recoge por primera vez el término "funcionario". Se recogen también las bases para el ingreso, el ascenso en la carrera administrativa, los derechos y categorías. Se recogían cinco categorías: jefes superiores, jefes de administración, jefes de negociado, oficiales y aspirantes a oficial. Se regulaba también todo lo referente a ascensos, sueldos y jubilaciones. Este Estatuto tuvo un desarrollo posterior en el Reglamento Orgánico de las Carreras Civiles al Servicio del Estado, que fue derogado, teniendo corta vida. Posteriormente se aprobaron las leyes de Presupuestos de 25 de junio de 1864 y de 15 de julio de 1865 en el que se establecen unas reglas para el ingreso y ascensos en las carreras de la Administración Civil económica, que más tarde amplió el Reglamento de 4 de marzo de 1866. Ellas por sí solas no bastaron para establecer una legalidad completa que encauzase el desbordamiento de injustificadas pretensiones; y si pueden considerarse como los primeros, aunque débiles pasos, dados en la organización del personal de la Administración del Estado, no han llegado a compensar las justas y apremiantes exigencias que sobre la necesidad de una buena ley de empleados ha manifestado la opinión pública. Como señala Beneyto la idea de Bravo Murillo sobre la administración era que esta era poco profesional, corrupta y muy ideologizada ${ }^{5}$. Uno de los aspectos que más se han destacado de la regulación impulsada por Bravo Murillo fue la de constituir el germen de los futuros Cuerpos de funcionarios y la de dividir estos entre Cuerpos Generales y Cuerpos Especiales 6 . En cuanto a la inamovilidad, como ya se ha apuntado, no está garantizada para los funcionarios de los Cuerpos generales, si bien los requisitos exigidos para el acceso a la Función Pública denotan un claro interés en garantizar la permanencia en el servicio. Otro aspecto importante apuntado, entre otros, por Jordana de Pozas, fue la creación de las Juntas de Jefes en cada Ministerio y una Oficina general o provincial. A través de dichas Juntas se ejercía la potestad disciplinaria sobre los funcionarios y se calificaban los méritos y servicios a efectos de ascensos. Pero, además, ejercía una función consultiva al jefe del departamento o de la oficina. Entre los aspectos positivos impulsados por Bravo Murillo, la consolidación

5 BENEYTO, J. "Familiares de empleados, recomendados de la superioridad o milicianos del último pronunciamiento, entraban en la covachuela como meritorios y, aún a veces, ya como escribientes, hasta conseguir el nombramiento de oficial, que les daba acceso al escalafón". Vid. "Historiade la Administración Española e Hispanoamericana”. AGUILAR. Madrid, 1958.

6 GARCÍA DE ENTERRÍA: "La Función Pública en España". Conferencia pronunciada en la Universidad de París I. 1972.

(c) UNED. Revista de Derecho UNED, núm. 26, 2020 
del principio de mérito en el acceso y la promoción, la clasificación por categorías, simplificando la organización administrativa. La determinación y concretización del sueldo de los funcionarios, el reconocimiento de los derechos y deberes de los funcionarios. Se criticó la limitación de las garantías del funcionario sobre el que recaía una sanción en virtud de la potestad disciplinaria ejercida por la administración. También la subordinación de la Administración a la jurisdicción. No se concretó la inamovilidad de los funcionarios de los cuerpos generales como derecho.

En 1866 se aprueba el Estatuto de O’Donnell, con el fin de limitar las funciones de los políticos y eliminar las arbitrariedades de la Administración. También quiere fomentar en los funcionarios el interés por prestar un buen servicio público. Se establecen una serie de categorías: Jefes Superiores, Jefes de Administración, Jefes de Negociado, Oficiales y Aspirantes a Oficiales, o sea mantiene la misma estructura que el Estatuto de Bravo Murillo, dejando fuera a los subalternos, quiénes no tendrán la consideración de empleados públicos. Barrachina ${ }^{7}$ distingue que el personal excluido de la categoría de funcionario según sus funciones:

- Por atención a sus funciones:

- Consejeros de Estado y empleados con funciones consultivas.

- Por organización especial

- Personal al servicio del Tribunal de Cuentas del Reino, Fiscal, Secretario General, oficiales mayores, tenientes fiscales, oficiales y aspirantes del Consejo de Estado.

- Por su especial instituto

- Los miembros de la carrera diplomática y consular, los ingenieros de los tres cuerpos civiles, los miembros del cuerpo de telégrafos, el profesorado, los empleados facultativos del ramo de estadística, los empleados de vigilancia, de cárceles y de presidios.

- Por el orden distinto de funcionamiento

- Los Jueces, Magistrados y funcionarios auxiliares de la Administración de Justicia y los miembros del Ministerio Fiscal.

7 E. BARRACHINA JUAN: "La Función Pública. Su Ordenamiento jurídico”. Parte General I. Ed. PPU. Barcelona, 1991. Pág. 131. 
El contenido de la reforma de $\mathrm{O}^{\prime}$ Donnell lo forman la Ley de 25 de junio de 1864, donde se establecen las reglas para el ingreso y ascenso en las carreras civiles de la Administración Pública y el Real Decreto de 4 de marzo d 1866, por el que se aprueba el Reglamento Orgánico de las carreras civiles de la Administración del Estado. El RD estaba formado por 91 artículos, divididos en 10 capítulos y cuenta, además con una disposición transitoria y una disposición final. El ingreso a la función pública lo regula a través de los principios de mérito y capacidad y la búsqueda de la estabilidad de los funcionarios. Como Señala García Trevijano ${ }^{8}$, el objetivo que tenían las medidas aprobadas era "no sólo favorecer el servicio y la buena marcha de los negocios administrativos sino, también, defender al Gobierno de las veleidades políticas, al no poder realizar nombramiento y separaciones arbitrarias". Importante también es el tema de la inamovilidad de los empleados públicos, concretamente en sus artículos 50,51 y 52 del Real Decreto de 1866 consagraban la estabilidad en el empleo para los empleados públicos que justificaran un número de años "su celo, su laboriosidad y su honradez". Los funcionarios que hubiesen prestado servicio durante, al menos, quince años sólo podrían ser separados por causa grave y previa audiencia al interesado e informe del Consejo de Estado. Los que llevaren de 6 a 15 años en la Administración sólo podían ser separados mediante expediente justificado, con informe de dos de sus jefes en los que se determinase que no reunían las condiciones de moralidad, aptitud, lealtad y aplicación necesaria para el buen desempeño de sus cargos. Por último, quedaban sujetos a amovilidad los que no llevaran más de 6 años en la Administración, salvo que hubieran obtenido sus cargos por oposición. El Estatuto de O’Donnel supone la definitiva regulación del derecho disciplinario, la mayor sistemática en la regulación del sistema de carrera de los funcionarios.

La Ley de 21 de julio de 1876 mantiene vigente el régimen de inamovilidad de los empleados públicos que no se halles organizados en cuerpos especiales.

El 6 de marzo de 1876 el Diputado José Puig Llagostera presenta en el palacio del Congreso, una Proposición de Ley, para que se estudie y se debata una propuesta de organización de la administración pública, en la que se lleve a cabo una carrera administrativa alejada fuera del foco, de los vaivenes y de la influencia política. Como señala Arroyo novedades importantes van a ser, el establecer un cri-

8 GARCÍA TREVIJANO- FOS, "Un desconocido precedente de la función pública española: el Estatuto de O’Donnell de 1866”, Revista Internacional de Ciencias Administrativas. Núm. 2-3, Pág. 145.

(C) UNED. Revista de Derecho UNED, núm. 26, 2020 
terio de idoneidad para el desempeño de funciones públicas, siempre que se acredite la titulación académica o supere los exámenes. El reconocimiento al derecho a la inamovilidad de los funcionarios que lleven prestando servicios efectivos un determinado período de tiempo

Así Puig Llagostera9 señala en la sesión del 8 de marzo dónde realiza la defensa de esta proposición:

"Se trata de reglamentar, moralizar la administración pública haciéndola en todos sus ramos una carrera honrosa y honrada, exente por completo de las influencias y oscilaciones políticas; es decir, a separar completamente la administración y la política ¿Hay nada de más imprescindible necesidad? Pues que, mientras la administración no esté separada de la política ¿Es posible la administración? En un país en que cambian con tan lamentable frecuencia todas las políticas, en que surgen a cada momento y por cualquier cuestión políticas y políticos en tan variada abundancia, en que el primer cuidado de todo partido o fracción al plantear su política es revolver la administración, repartiendo entre los suyos los destinos, ¿no resulta acaso ser la administración, es decir, el presupuesto, el cebo, el despojo, el botín expuesto a la codicia de todos los partidos".

Puig Llagostera expresa con mucha nitidez cual es el problema que tenía la administración pública del año 1876, como era su excesiva politización, administración y partidos políticos estaban muy unidos. Produciéndose un reparto de los cargos públicos cada vez que uno u otro partido accedía al poder. Con ello el problema que se planteaba, es que no se producía una profesionalización de la administración pública, sino más bien como dice el mismo diputado ${ }^{10}$ "a la que se dedicarán todos los que se sientan con poca aptitud o con poca afición para el trabajo y con espíritu aventurero".

Defiende el diputado que se siga el ejemplo de otros países, en los que se producen cambios políticos e incluso cambios de regímenes políticos del Imperio a la República, sin que ello suponga una renovación absoluta de la administración y por eso plantea esta propuesta de ley para que sea refrendada por la cámara del Congreso de los Diputados. A las palabras del diputado Puig Llagostera, le replicó el Ministro de la Gobernación, Romero Robledo primero defendiéndose en cuanto a la acusación de que lo único que buscan los políticos cuando llegan al gobierno es la petición de credenciales y de car-

9 Diario de Sesiones del Congreso de los Diputados de 8 de marzo de 1876, $\mathrm{n}^{\circ}$ 17, Pág. 294.

10 Idem. 
gos. Para después reconocer que es un mal que viene de antiguo y que el Gobierno actual tenía en mente modificar:

"Es indudable que el gobierno actual pensaba ocuparse de esto, y en garantía de este pensamiento hay una prueba convincente, y es que ese reglamento que la proposición de S.S. pide que se ejecute hasta tanto que se examine y vote una ley, ha sido planteado por un Gobierno de que de que formaban parte el Sr. Presidente del Consejo de Ministros y el Señor Ministro de Hacienda del actual Gobierno".

Se acordó en dicha sesión que esta Proposición de Ley pasase a la sección y se eligió una comisión de miembros de todos los partidos políticos, para negociar esa carrera administrativa.

En su réplica el Sr. Puig y Llasgostera ${ }^{11}$ responde con mucha ironía "Yo recuerdo haber visto en uno de los corredores de este Congreso cogido, como vulgarmente se dice, entre la espada y la pared, cogido un Sr. Ministro entre la pared y un Diputado, que con un paquete de pretensiones de destino se las iba espetando una tras otra a boca de jarro, amenazándole con que si no le satisfacía en un plazo perentorio que le fijó, se pasaría a la oposición. Yo creo, Sres. Diputados, que el país nos envía aquí para algo más que para pedir destinos".

Sobre la proposición de ley relativa a la carrera administrativa del Estado, se nombró como miembros de la comisión ${ }^{12}$ a los Sres. De la Villa de Miranda, Serrano Alcázar, Puig y Llagostera, Vicuña Angel Escobar, Guiraro y Navarro de Ituren.

Se reunió la Comisión, que había sido propuesta por el Sr. Puig y Llagostera, que fue quién actuó como Presidente, quien negoció y acercó posturas entre los representantes de los distintos partidos con representación en la cámara buscando el consenso de todos ellos. El Sr. Puig negoció con los representantes de todas las fuerza políticas, con aquellos con los que tenía menos afinidad, y más diferencias en cuanto a ideología como el Sr. Castelar, hasta con aquellos con los que tiene más afinidad y eran más amigos del Gobierno.

El Sr. Guirao criticó que el que se haya creado una comisión de diputados, para que estos trasladen al Congreso el nombramiento de una comisión y que sea este el que lo estudie, considerando que la redacción del Sr. Puig y Llagostera era errónea. Añadiendo que quiere decirle al Sr. Puig que no desconfíe en la postura de este Gobierno, ya que él personalmente conoce la postura a favor e este de

11 Idem, pág. 295.

12 Idem. Pág. 555.

(C) UNED. Revista de Derecho UNED, núm. 26, 2020 
proyecto de ley tanto del Sr. Presidente del Consejo y del Sr. Ministro de la Gobernación. El Señor Puig y LLagostera ${ }^{13}$, le rebate diciendo que el Gobierno hasta ahora no ha mostrado nada más que buenas palabras y buenos deseos, y que tiene el presentimiento de que el Gobierno no va a hacer nada, y que esa ley no se votará en el Congreso de los Diputados.

El diputado Sr. Domínguez plantea que mientras se debate la propuesta de ley se apruebe de forma provisional el reglamento orgánico de la carrera de la Administración Pública de 4 de marzo de 1866. A esta propuesta el Sr. Guirao ${ }^{14}$ entiende que el reglamento tiene algunos defectos. Sin embargo distingue el reglamento de forma muy clara la separación entre empleados exclusivamente políticos y los empleados exclusivamente administrativos. En la misma intervención el Sr. Guirao aprovecha para recriminar al Sr. Domínguez para recordarle que no quieren que se aprueba el reglamento para que no suceda lo mismo que con el reglamento de 4 de mayo de 1866, a la instrucción de 1850 y los Reales Decretos del 52 y 53 sobre esta materia.

En la legislatura de 1872, el Diputado Moreno Rodríguez ${ }^{15}$ planteó una proposición de ley para que se nombre una comisión de siete Diputados para que presenten la deliberación de las Cortes un proyecto de ley orgánico de las carreras civiles de la administración pública, en la que se regularice el ingreso, ascenso y remoción de los empleados.

En la legislatura de 1873, el día 12 de marzo de 1873, el Diputado Sr. Cisa ${ }^{16}$ presentó una proposición sobre la aprobación de un nuevo plan general de administración pública. El Diputado plantea que existe en los actuales servicios públicos mucha complicación, y que se hace indispensable un cambio radical en las reformas de todas las oficinales del Estado partiendo de la base de suprimir todas las Direcciones, así como las intervenciones, y que aquellas que se abran por la mañana de ocho a doce, y por la tarde de dos a seis, con lo cual se ahorran cuando menos la mitad de los empleados y se evitará que los expedientes se eternicen en las oficinales, en las cuales no deben estar por más tiempo de quince días.

13 Idem. Pág. 1193.

14 Idem. Pág. 1924.

15 Diario de Sesiones, legislatura 1872-73, Asamblea Nacional de fecha 10 de diciembre de $1872 \mathrm{n}^{\circ} 75$, pág. 2243.

16 Diario de Sesiones, legislatura 1873, Asamblea Nacional de fecha 12 de marzo de 1873 n 22 pág. 529. 
El principal intento de aprobación de una auténtica carrera administrativa, lo plantea el diputado Sr. Puig y Llagostera ${ }^{17}$, mediante proposición de ley, en la que se proponía una nueva organización de la carrera administrativa, planteada el 6 de marzo de 1876, siendo presidente Emilio Castelar.

El diputado Sr. Durán y Bas ${ }^{18}$ presentó una proposición de ley por la que se plantea la reforma de la administración en España.

El 21 de octubre de 1881 se plantea en la sesión de las cortes de 21 de octubre de 1881 una proposición de ley del diputado Sr. Becerra $^{19}$ por la que se determinan las condiciones que deben cumplir los diputados provinciales, los secretarios de las Diputaciones y los secretarios de Ayuntamiento para el ingreso en las carreras de la administración pública. Este acceso se permitía para aquellos que hubiesen sido elegidos en dos o más elecciones generales y hayan ejercido el cargo más de dos años en las Comisiones permanentes precisamente de dichas corporaciones y tengan el título de licenciados en derecho civil y canónico o administrativo. Podrán ingresar en las carreras de la administración pública, salvo aquellos que se rijan por los reglamentos especiales conforme establece el Real Decreto de 18 de junio de 1852. También se permitía a los secretarios de las Diputaciones provinciales que siendo letrados hayan obtenido el cargo por oposición y tengan una antigüedad en el cargo de dos años. Estos podrán ingresar en la administración pública con destinos de la categoría correspondiente al sueldo que disfrutaran. También podrán acceder aquellos secretarios de Ayuntamiento que sin nota en su expediente, aunque carezcan de título académico, reúnan más de diez años de servicios efectivos en el cargo, y dos de ejercicio con el mayor sueldo, que será el regulador para determinar su categoría, podrán igualmente ingresar con la que corresponda en destinos de la administración pública. A partir de la Ley de Presupuestos de 1876, que fue aprobada por el gobierno de Cánovas del Castillo se recoge dentro de la función pública, una clara diferenciación entre la carrera general y los cuerpos especiales. Como señala Oliva de Castro y Gutiérrez Reñón ${ }^{20}$. Posteriormente se aprueba la Ley de 2 de marzo de 1917, por la que el Gobierno realiza una reforma conocida con el nombre de "Ley de Autorizaciones", que dio lugar a la promulgación

17 Diario de Sesiones, Serie Histórica, Legislatura 1876-77. Apéndice primero al $\mathrm{n}^{\circ} 17$, Apéndice primero al $\mathrm{n}^{\circ} 17$.

18 Diario de Sesiones, Serie Histórica, Legislatura 1879-780. Nº 17, pág. 179.

19 Diario de Sesiones, Serie Histórica, Legislatura 1881-82. Apéndice $4^{\circ}$ al $\mathrm{N}^{\circ} 28$.

20 de la OLIVA de CASTRO A. y A. GUTIÉRREZ REÑ́N: «Los Cuerpos de Funcionarios», Documentación Administrativa, núm. 124, agosto, 1968. 
de la Ley de Bases de 1918. Esta ley va a recoger el personal técnico y auxiliar, que se organiza en dos escales independientes: La escala técnica se divide en 3 categorías: Jefes de Administración, Jefes de Negociado y Oficiales.

Cada una de estas clases se divide en 3 categorías. El ingreso a la categoría técnica se hace normalmente por la categoría y clase inferior (oficial de 3.a clase). El ingreso se hace por oposición, a la que podrán presentarse quienes tengan un título de enseñanza superior o pertenezcan a la Escala Auxiliar con cuatro años de servicios. Los aprobados en la oposición serán nombrados aspirantes y habrán de superar un curso selectivo organizado por el Ministerio respectivo. También reserva para el ingreso por oposición libre una quinta parte de las vacantes de Jefe de Negociado de 3.a clase y de Jefe de Administración de 3 .a clase.

La carrera administrativa civil se establece en clara similitud con la carrera militar. La escala auxiliar se corresponde con la categoría de suboficiales. Y las tres categorías del servicio técnico: Oficiales, Jefes de Negociado y Jefes de Administración se corresponden con las tres categorías militares de Oficiales, Jefes y Generales y comprenden un número equivalente de grados. Desde un punto de vista funcional, las tres categorías que se establecen en el servicio técnico se corresponden a tres niveles que pueden observarse en la actividad administrativa. Un nivel superior claramente directivo: los Jefes de Administración. Un segundo nivel de mando intermedio: los Jefes de Negociado (no olvidemos que en la organización de la época el negociado tenía una importancia muy superior a la actual, igual o superior a los actuales Servicios). Y un tercero de carácter ejecutivo: los Oficiales. Esta ley intenta unificar y fusionar todos los escalafones de funcionarios administrativos. A la vez, la Ley prevé una reducción de plantillas (que habrá de importar al menos una tercera parte de los gastos de personal) a fin de financiar en parte los aumentos de sueldos concedidos. La Ley de 30 de junio de 1892 vuelve a introducir modificaciones del Estatuto de 1852, que va a establecer la obligación de formar escalafones por estricta antigüedad. También promete, como las leyes anteriores la aprobación de una legislación específica que regule el Estatuto de los funcionarios, ley que no llegará hasta que llega al Gobierno Antonio Maura en 1918. Es este un periodo de fuerte crisis, en la que los funcionarios de clases más bajas viven casi en la miseria. Son periodos de crisis sociales, de rebeliones militares. Tras la huelga general de 1917, se constituye un Gobierno de concentración nacional, presidido por Antonio Maura, quién va a luchar contra el caciquismo y lleva a cabo una reforma 
de la Administración. Para ello busca conocer quién toma las decisiones, para así exigir la responsabilidad personal del funcionario. Así se va a establecer la Ley de Responsabilidad Civil de los funcionarios públicos del orden gubernativo y administrativo, aprobada el 5 de abril de 1904. Es la denominada "Ley de responsabilidades". El artículo 1 de esta ley establece "Los funcionarios civiles del orden gubernativo, cualquiera que sea su clase y categoría, desde ministro de la Corona hasta Agente de la Autoridad, que en el ejercicio de sus cargos infringen con actos $\mathrm{u}$ omisiones un precepto cuya observancia les haya sido reclamada por escrito, quedarán obligados a resarcir al reclamante agraviado de los daños y perjuicios causados por tal infracción legal".

Esta ley va a ser la base que culminará con la aprobación del Estatuto de 1918. Ley con un tinte conservador, así por ejemplo, prohíbe a los funcionarios el derecho de huelga y limita el derecho de asociación. La aprobación del Estatuto de Maura como indica Nieto $^{21}$ se trataba de una competencia que correspondía a las Cortes Generales y que, sin embargo, había sido asumida por el Gobierno mediante Decreto, amparándose, eso sí, en la autorización parlamentaria que otorgaba la Ley de Autorizaciones dictada en 1917".

Se regulan los derechos pasivos de jubilación, retiro, viudedades y orfandad.

Entre las principales novedades del estatuto, destacar el establecimiento del sistema de oposición como ingreso en la función pública. Se da continuidad a que los ascensos sean conforme a los criterios de antigüedad, oposición y libre designación. Se establece la jubilación forzosa a los 67 años y la voluntaria a los 65 . Se establece la permuta, autorizada dentro del mismo escalafón, entre funcionarios de igual clase y categoría y previo informe de los jefes inmediatos de los solicitantes. Se establecen las siguientes situaciones administrativas: Excedencia (voluntaria o forzosa), separación del servicio o cesantía, jubilación (voluntaria, forzosa o por imposibilidad física). Se recogen una serie de recompensas como son la mención honorífica, premios en metálico y las condecoraciones. En materia disciplinaria se establece que las faltas cometidas por los funcionarios podrán ser leves, graves o muy graves, pudiendo ser sancionadas con las siguientes sanciones: apercibimiento; traslado; suspensión de empleo y sueldo; pérdida de uno a veinte puestos en el escalafón; postergación perpetua; y, por último, cesantía o separación definitiva del servicio. Finalmente, se reconoce el derecho de

21 Vid. A. NIETO GARCÍA: "Estudios históricos sobre Administración...” op. cit

(C) UNED. Revista de Derecho UNED, núm. 26, 2020 
asociación de los funcionarios con el fin de que puedan defender sus intereses. Estas asociaciones tenían personalidad jurídica propia, si bien el Gobierno podía decretar su disolución en cualquier momento. La disposición transitoria primera crea una categoría a extinguir que es la de los Oficiales cuartos, en la que se integran los aspirantes o auxiliares existentes, así como los temporeros que prestaban servicios análogos a los aspirantes. A estos Oficiales cuartos se les reconoce el derecho a cubrir automáticamente las vacantes no amortizables de la Escala Técnica. Además, se prevé una reducción de las plantillas para financiar los aumentos de sueldo concedidos, lo que unido a lo anterior retrasará sine die la selección de nuevos funcionarios con los criterios de mérito y capacidad previstos en la Ley. Por otra parte, la Ley deja su desarrollo posterior en manos de los Departamentos ministeriales. Criticada fue la falta de conexión entre los cuerpos de los funcionarios, Gutiérrez Reñón señala que "la falta de conexión entre la categoría personal y el nivel de los puestos de trabajo constituyó, probablemente, el auténtico aspecto más criticado del sistema, la clave de su vulnerabilidad y, en definitiva, de su degradación ante la presión continuada de diversos factores y, muy especialmente, del deterioro de las retribuciones"22.

\section{NOCIÓN DE CARRERA PROFESIONAL}

La denominación "carrera" es muy amplia e indeterminada. Enmarcado en la definición tradicional de "carrera administrativa" o en la más extensa y descriptivo de "carrera profesional en la función pública o en el empleo público”. Esta última es la más gráfica y la que mejor explica el concepto. Ya que define que quienes realizan la carrera son los funcionarios o empleados públicos, ya que dedican su vida profesional al servicio público y para ello intentan ascender dentro de la administración.

El vocablo carrera no deja de tener una vinculación con los derechos y garantías encuadrados en las atribuciones que pertenecen al funcionario. En aras de la búsqueda de una administración moderna, eficaz, eficiente y profesional. Es un sinónimo de "ascenso, promoción”, de intentar ocupar los puestos más elevados dentro de la jerarquía de puestos de trabajo. Se trata de que se cumpla la carrera administrativa, evitando una politización de la administración

22 Vid. GUTIERREZ REÑÓN A.: "La carrera administrativa en España: evolución histórica y perspectivas. Revista Documentación Administrativa 210-211. INAP. Madrid, 1987. 
pública. Que el acceso sea mediante unas oposiciones dónde prevalezcan los méritos de publicidad, mérito y capacidad. En el actual sistema de "carrera", el ascenso se produce mediante el "concurso" y en algunos casos de "concurso-oposición".

Se trata también de que el funcionario tenga un incentivo que se puedan cumplir sus expectativas de desarrollo profesional. Para ello el funcionario tendrá también que conseguir la titulación exigida en cada uno de los cuerpos a los que quiera promocionar. Por ello hay que unir la promoción a la formación, todo ello en la búsqueda de una modernización de la administración de justicia. Al referirnos a la carrera administrativa está relacionado con el de servidor público, con el de valores en servicio de la sociedad. En los últimos años al referirnos a la "carrera administrativa" se ha ido sustituyendo por el de puesto de trabajo. Estas son las características del "modelo de carrera", el cual sigue vigente. Pero no es menos cierto que en los últimos años la idea tradicional del "modelo de carrera" como sistema colectivo o "cerrado" está dando paso a la introducción de muchos elementos propios del modelo de empleo (o de puesto de trabajo). De hecho, se está produciendo una cierta "asociación" entre ambos modelos, puesto que uno y otro están importando elementos entre sí, de tal modo que hasta en el sistema de empleo existe un "sistema de carrera". En este sentido, los diferentes documentos de la OCDE y la doctrina especializada profundizan en este proceso de aproximación entre los dos modelos. La Ley 7/2007, de 12 de Abril, del Estatuto Básico del Empleado Público, con carácter de norma básica estatal para todas las administraciones públicas españolas, ya recogía tanto la definición de la carrera profesional, como sus principios y modalidades. La carrera profesional horizontal supone el establecimiento de un modelo retributivo mediante una serie de niveles de desarrollo profesional, con respeto a los principios de igualdad, mérito y capacidad y que permite la progresión profesional del personal funcionario sin la necesidad de un cambio de puesto de trabajo. Se entiende por carrera profesional horizontal el derecho de los empleados públicos a progresar de forma individualizada y al reconocimiento de su desarrollo profesional, en cuanto a conocimientos, formación, experiencia profesional y cumplimiento de los objetivos establecidos por la Administración y como se ha indicado anteriormente sin necesidad de cambiar de puesto de trabajo. Básicamente, se tienen en cuenta tres pilares fundamentales en los que se sustenta el establecimiento de un sistema de carrera profesional: - Evaluación del desempeño. - Formación. - Antigüedad. 


\section{LA PROMOCIÓN INTERNA: LA CARRERA ADMINISTRATIVA DEL FUNCIONARIO Y LA CARRERA VERTICAL DEL FUNCIONARIO}

La promoción interna presenta dos modalidades. A saber: La promoción interna vertical, que consiste en el ascenso desde un cuerpo o escala de un Subgrupo, o Grupo de clasificación profesional en el supuesto de que éste no tenga Subgrupo, a otro superior, de acuerdo con lo establecido en el artículo 18 y la promoción interna horizontal, consistente en el acceso a cuerpos o escalas del mismo Subgrupo profesional, de acuerdo con lo dispuesto en el artículo 18. Los requisitos establecidos son la promoción en años de servicio activo en el inferior Subgrupo, o Grupo de clasificación profesional, en el supuesto de que éste no tenga Subgrupo y superar las correspondientes pruebas selectivas. Consiste la carrera vertical en el ascenso en la estructura de puestos de trabajo por los procedimientos de provisión previstos legalmente, en esencia, el concurso y la libre designación con convocatoria pública. Tanto en uno como en otro, la valoración de los méritos, capacidades y aptitudes necesarios para el desempeño de los puestos habrá de ser asumida por expertos. Esta promoción se basa en los puestos de confianza, como antes hemos denominado de libre designa Jiménez Asensio ${ }^{23}$ al referirse a la carrera administrativa y la profesionalización de los funcionarios "La facultad de decidir hasta donde llega la carrera funcionarial y donde empieza el nivel político en la estructura, aparte de ser uno de los temas más vidriosos y de más difícil concreción práctica, supone un factor de innegable importancia estructural que incide tanto sobre la selección, como sobre la formación y carrera".

\section{1. LOS PUESTOS DE LIBRE DESIGNACIÓN}

Los puestos más elevados de la administración, se cubren en la actualidad a través de cargos políticos, que son designados mediante libre designación. Así el cargo de Ministro, Secretario de Estado, Subsecretario, Director General y sus equivalentes autonómicos son cubiertos conforme al factor de la confianza. Para el cargo concreto de Director General es necesario la condición de funcionario perteneciente a un cuerpo para cuyo ingreso se exija el titulado de Grado. En muchos de estos cargos se exige una especialización técnica o

23 JIMÉNEZ ASENSIO, R. Selección, formación y carrera administrativa en la Función Pública Vasca "Documentación administrativa" número 204, abril- junio, 1985, pág. 51 
del sector que corresponda que cumplen en mayor grado los funcionarios que personas ajenas, que son nombradas sólo en base la confianza y no al de cualidades profesionales para el cargo. La libre designación ya aparece en los textos preconstitucionales, en el Decreto núm. 315/1964, de 7 de febrero, Texto Articulado que aprueba la Ley de Funcionarios Civiles del Estado, dónde se recoge la posibilidad de provisión como de libre designación, a propuesta de la Comisión Superior de Personal. También se recoge en el Decreto número 1106/1966 de 28 de Abril, que aprueba el Reglamento para la provisión de vacantes En su art. 2 establece "sólo podrán proveerse mediante el sistema de libre designación los puestos de trabajo que excepcionalmente se califiquen como tales a iniciativa de los Ministerios interesados. La Administración del Estado, por Orden del Ministerio de la Presidencia de fecha 15 de enero de 1986, sobre relación de puestos de trabajo en desarrollo de la Ley 30/84 publicada al día siguiente de Real Decreto 2617/1985, que da instrucciones a todos los Departamentos en su apartado octavo, forma de provisión, y establece "Al formular la correspondiente propuesta deberá tenerse en cuenta que... el procedimiento de concurso deberá ser el propuesto normalmente, reservándose el de libre designación, con carácter restringido, para puestos con nivel de complemento de destino, correspondiente entre 26 (inclusive) y 30 en que así estrictamente se considere necesario y excepcionalmente en supuestos debidamente justificados para los puestos de nivel inferior a 26 ".

Para el resto de cuerpos en la administración pública, por debajo de los cargos políticos, se tienen que cubrir por concurso de méritos y libre designación, conforme establece el art. 78.2 del Estatuto Básico del Empleado Público, Texto Refundido aprobado por Real Decreto Legislativo 5/2015, de 30 de octubre. Debe cumplir además el requisito de ser funcionario perteneciente a un cuerpo de la administración del Estado, por lo que ha superado una oposición para acceder a su plaza. Conforme establece el Reglamento General de Ingreso del Personal al servicio de la Administración general del Estado y de Provisión de Puestos de Trabajo y Promoción Profesional de los Funcionarios Civiles de la Administración general del Estado, aprobado por Real Decreto 364/1995, de 10 de marzo, en su art. 56.2 establece que la decisión deberá ser motivada y que para dicha motivación será suficiente con una reseña "al cumplimiento por parte del candidato elegido de los requisitos y especificaciones exigidos en la convocatoria, y la competencia para proceder al mismo".

El TREBEP expone que sólo puede emplearse en puestos "de especial responsabilidad y confianza" (art. 80.2), lo que remite por un 
lado a puestos "directivos" (aunque los más importantes son de tipo político o altos cargos de organismos públicos, que ya hemos visto que se someten a otras reglas), y también los puestos de secretaría de determinados altos cargos, donde prima el factor de la confianza. En este contexto no es mucho el avance experimentado cuando un cargo deja de ser objeto de un nombramiento "político" y pasa a estar sujeto al procedimiento "funcionarial" de libre designación (es la diferencia que existe, por ejemplo, entre el nombramiento de un Director General y el de un Subdirector General), puesto que ambos casos el único límite efectivo se encuentra en los requisitos funcionariales que se exigen a los candidatos.

Mención aparte se produce en el nombramiento para cargos judicial, dónde la LOPJ, prevé en su art. 333 la libre designación. Desde las presidencias de órganos colegiados. No es nada fácil justificar desde el punto de vista del mérito y capacidad y de la independencia judicial, que en todos esos puestos el factor evidente la confianza del órgano judicial que efectúa el nombramiento.

Se produjo una modificación del TS, de su jurisprudencia, pasando de decir que "la libre designación o el nombramiento discrecional sólo puede apoyarse en la existencia o inexistencia de motivos de confianza que el Órgano de Gobierno competente para formular la propuesta puede apreciar libremente sin estar sometida al requisito formal de la motivación" 24 y exigir motivación porque la elección basada en criterios de confianza establece el Tribunal "resulta de imposible traslación a la provisión de vacantes jurisdiccionales, más todavía a las que conllevan esa labor de dirección de un órgano jurisdiccional colegiado", en las que -comentando lo dicho en reiteradas ocasiones por el Tribunal Europeo de Derechos Humanos y por el Tribunal Constitucional- incluso las apariencias pueden ser importantes, cuando lo que está en juego es la confianza que los Tribunales de una sociedad democrática deben merecer a los que acuden a ellos".

Se trata de que el órgano que decide el procedimiento de libre designación indique los méritos que se han considerado más importantes para elegir entre los diversos candidatos, y por qué considera que el aspirante elegido es el que los tiene de manera más destacada. Destacar también una reciente sentencia, de 19 de septiembre de 2017, del Juzgado de lo Contencioso-Administrativo número 4 de

24 STS de 30 de noviembre de 1999, recurso contencioso-administrativo 449/1997), se declara superada esta doctrina (STS de 29 de mayo de 2006, recurso contencioso-administrativo 309/2004) 
Oviedo (sentencia 212/2017), que anula un nombramiento de libre designación porque el órgano competente no había procedido previamente a valorar los méritos de los distintos candidatos (en suma, por falta de motivación): "no existe ninguna explicación ni ninguna motivación del nombramiento controvertido sino, simplemente, consta una propuesta de nombramiento".

La sentencia reclama directamente al artículo 23.2 de la Constitución y también a un argumento indirecto: si la libre designación sólo está justificada en puestos de especial responsabilidad, que se corresponden grosso modo con el personal directivo al que se refiere el artículo 13 del TREBEP, habrá que aplicar también lo que este precepto señala para la selección de este personal, que debe estar basada en procedimientos de "mérito y capacidad, ( ) idoneidad, ( ) publicidad y concurrencia". Como dice la sentencia,

"no hay duda de que la libre designación no puede implicar un nombramiento huérfano de cualquier valoración ( ). Así se deduce, aun cuando sea indirectamente, de la normativa aplicable al personal directivo ( ), por lo que, con mayor razón, habrá de aplicarse a los puestos ordinarios ocupados por empleados públicos".

En este caso se da la circunstancia, especialmente tenida en cuenta por la sentencia, de que el puesto no estaba reservado a funcionarios o personal estatutario, sino que podía elegirse a una persona ajena a la Administración, que se incorporaría directamente a este puesto directivo (sin adquirir, obviamente, la estabilidad laboral del funcionario, puesto que de este puesto también puede ser libremente removido):

"también en los casos de libre designación y, a fortiori, especialmente cuando se abre la convocatoria a personal ajeno a la condición de personal estatutario, habrá que observar las exigencias de igualdad, mérito y capacidad. Si no se actúa así, esta vía de la libre designación, que en este caso recae sobre personal que no está vinculado previamente a la Administración, se convierte en una vía para el ejercicio de la arbitrariedad o del mero capricho en manos de la Administración para el nombramiento de determinados puestos que, por regla general, deben ocupar empleados públicos".

Incluso teniendo en cuenta las características del caso concreto, esta doctrina, que llega por otra vía al mismo resultado de la jurisprudencia sobre nombramientos judiciales, podría y debería generalizarse en los nombramientos por libre designación. Pues bien, esta forma de entender la discrecionalidad permite explicar el cambio judicial en el control de la libre designación. En el concurso de méritos, esos criterios que completan la norma y que permiten acotar el 
margen de decisión del órgano competente, se fijan en la convocatoria, en forma de baremo. Lo que la jurisprudencia está exigiendo en la libre designación es que esos criterios existan, aunque sean fijados después de la convocatoria, ya a la vista de los candidatos, y se expliciten sólo en la resolución del procedimiento. Se convierte en un procedimiento de provisión de puestos de trabajo que hasta no hace mucho era, como su nombre sigue indicando, "libre".

\section{CONCLUSIONES}

A lo largo de la historia la ordenación de la carrera administrativa se desarrolla a través de la profesionalización de la Administración pública. El acceso a la función pública se tiene que realizar a través de los principios de mérito, igualdad y capacidad. Por eso, históricamente, la ordenación de la carrera administrativa surge como disyuntiva al clientelismo político. Otro de los rasgos característicos de la función pública es el de inamovilidad, sistema que se ha establecido a través del modelo de "sistema de puestos de trabajo" en el que no hay una carrera administrativa como tal, sino que el funcionario ocupa un puesto de trabajo que deja de ocupar, tras su cese, renuncia o supresión del puesto y el sistema de "carrera". Sistema que parte de la base de que los funcionarios ejercerán a lo largo de su vida laboral sus funciones en diferentes puestos de trabajo, por tanto toman como referencia la actividad profesional y no el puesto específico de trabajo. En este sistema se valoran la práctica adquirida a través de la antigüedad. La administración tiene que atraer y retener a los mejores profesionales, a los más cualificados. El funcionario es además la garantía de la neutralidad en su actividad, sin connivencia con el poder ejecutivo.

El modelo de carrera administrativa de todas las administraciones públicas tanto las del Estado, como las transferidas a las CCAAS son un modelo consumido. En el que se producen situaciones en las que no hay verdadera carrera administrativa, otras en las que las carreras son muy cortas y no hay muchos ascensos. En otros casos, hay funcionarios que ascienden rápidamente, en muchos casos mediante la creación de puestos "a medida". Todo ello, provoca una desmotivación en el funcionario, especialmente en los funcionarios de más alto nivel, de los que depende el correcto funcionamiento de la administración pública. El sistema de libre designación va en contra de la libertad y de los méritos del funcionario. Para obtener el cargo tiene más valor el tener la confianza de un partido político que tener los méritos y las capacidades exigibles para el desempeño 
del cargo. Entran en vulneración dos normas constitucionales. Por un lado el de las condiciones de igualdad en el acceso a los cargos y funciones públicas, recogido en el art. 23.2 de la CE y el de los principios de capacidad y mérito, contemplado en el art. 103.3 de nuestra norma básica fundamental.

\section{VI.REFERENCIAS BIBLIOGRÁFICAS.}

AA.VV..: Informe sobre el Estatuto Básico del Empleado Público, Ayuntamiento de Madrid/Aranzadi, Madrid, 2008.

Albaladejo Campoy, M.: Pasado, presente y futuro de la Función Pública española. Cuadernos Económicos del ICE. Núm. 13. Madrid, 1980.

Álvarez Álvarez, J.: La Función Pública Española: evolución histórica y situación actual, en VV.AA: Administración y Función Pública en Iberoamérica. INAP. Madrid, 1989. - -ÁLVAREZ-GENDÍN, S.: El problema de las incompatibilidades de los funcionarios públicos, Revista de Administración Pública n 39. 1962.

Allí Aranguren, Juan Cruz, La construcción del concepto de Derecho administrativo español, Madrid, Thomson-Civitas, 2006.

Arenilla SÁEz, Manuel "La ciencia de la administración en la época de Oliván” en VVAA. La configuración jurídico-política del Estado liberal en España, Huesca, Universidad de Zaragoza, 1997, págs. 175-200.

Arlegui Bravo, R.: Derechos y deberes de los funcionarios. Pamplona, 1977.

ARroyo YANES, L.M.: La carrera administrativa de los funcionarios públicos, Tirant lo Blanch, Valencia, 1994.

La ordenación de la función pública contemporánea: la carrera administrativa (1808-1963), IAAP, Junta de Andalucía, Sevilla, 1996.

BarRachina JuAn, E.: La Función Pública. Su Ordenamiento Jurídico. Parte General I. Ed. PPU. Barcelona, 1991.

Beneyto, J.: Historia de la Administración Española e Hispanoamericana. AGUILAR. Madrid, 1958.

Blanco Gaztañaga, C.: "La carrera administrativa", Presupuesto y Gasto Público, 4-2005. 
Clavero Bartolomé, Manual de historia del constitucionalismo español, Madrid, Alianza, 1996.

Beneyto, J.: Historia de la Administración Española e Hispanoamericana. AGUILAR. Madrid, 1958.

Cuesta De La Hoz, A.: Incompatibilidades de los funcionarios. Cuadernos de Documentación. INAP. Mayo, 1984.

Del Rey Guanter, S. (Director): Comentarios al Estatuto Básico del Empleado Público, La ley, 2008.

Del Moral Ruiz, J.: Las funciones del Estado y la articulación del territorio nacional en VV.AA: Estado y territorio en España. 18201930. CATARATA. Madrid, 2007. ESCUIN PALOP, V.M.: El acceso del personal y la provisión de puestos de trabajo en la Administración del Estado y de las Comunidades Autónomas. Madrid, 1986.

García de Enterría, E: 242 - Apuntes de Derecho Administrativo. Tomo V. Universidad ComplutenseFacultad de Derecho. Madrid 1970. - La Función Pública en España. Conferencia pronunciada en la Universidad de París, 1. 1972. GARCÍA GALLO, A.: El Estatuto de los empleados públicos según los Reales Decretos de 1844 y 1852. Anuario de Historia del Derecho Español no 41.1971

García Martín, J. “La contestación al discurso de la Corona en la reglamentación parlamentaria del siglo XIX español. Análisis histórcio-jurídico, en Fuentes Ganzo, Eduardo y Martín,, José Luis (dir.) De las Cortes históricas a los Parlamentos democráticos, Madrid, 2003.

Garrido Falla, Fernando, Comentarios a la Constitución, Civitas, 1980,

Gorriti Bontigui, M., ToÑa GüEnaga, F.: "El nuevo modelo desorganización y recursos humanos en la Administración General de la Comunidad Autónoma del País Vasco".

GutierRez ReÑon, A.: "La carrera administrativa en España: evolución histórica y perspectivas" en Documentación Administrativa $n^{\circ} 210-211$

FÉREZ FERNÁNDEZ, M.: La carrera administrativa: nuevas perspectivas, Diputación de Barcelona, Barcelona, 2006.

FERNáNDEZ, Tomás Ramón, "La administración del Estado a lo largo del siglo XX"

García de Enterría, E: 242 - Apuntes de Derecho Administrativo. Tomo V. Universidad Complutense Facultad de Derecho. Madrid 
1970. - La Función Pública en España. Conferencia pronunciada en la Universidad de París, 1. 1972. GARCÍA GALLO, A.: El Estatuto de los empleados públicos según los Reales Decretos de 1844 y 1852. Anuario de Historia del Derecho Español no 41. 1971

JimÉnez ABAD, Manuel, Consideraciones en torno a la reforma de la función pública española en el Estado de las autonomías. En "Jornadas sobre la Función Pública de las Comunidades Autónomas", celebradas en Valencia, 1983. Servicio de Publicaciones de la Generalitat Valenciana

Jiménez Asensio, R.: Políticas de selección en la función pública española (1808-1978), MAP. Madrid, 1989.

Cuerpos generales versus cuerpos especiales: la fragmentación de la función pública española en el siglo XIX. Revista Vasca de Administración Pública nº 23. Bilbao, 1989.

Jordana De Pozas, L.: - Bravo Murillo y los funcionarios públicos. En VV.AA. Primer centenario de Don Juan Bravo Murillo. Madrid, 1952. Pág. 68. - Situación y necesaria reforma del Estatuto de los funcionarios públicos. En Estudios dedicados al profesor Gascón y Marín en el cincuentenario de su docencia. Madrid, 1952. Pág. 67 JUNQUERA GONZÁLEZ, J. Y GONZÁLEZ-HABA GUISADO, VM.: Las retribuciones de los funcionarios públicos. Asociación Española de Administración Pública. Madrid, 1979. LINDE PANIAGUA, E.: Notas sobre la naturaleza, el ámbito y el desarrollo del Estatuto Básico del Empleado Público. Colex. Madrid, 2008. LOBATO BRIME, F.: Las retribuciones de los funcionarios públicos. Revista Municipalia 338. Madrid, 1983. LÓPEZ-CHAVES Y CASTRO, I.: As reformas de López Ballesteros na Función Pública. III Simposio de Historia da Administración Pública. Santiago de Compostela, 1996 LÓPEZ RODÓ, L.: La reforma administrativa en España. Revista Documentación Administrativa, número 1. INAP. Madrid.

LoRente SARIÑEna, Marta y Garriga, Carlos "Responsabilidad de los empleados públicos y contenciosos de la Administración (181245). Una propuesta de revisión en Iñurritegui, José María y Portillo, José María (eds.) Constitución en España: orígenes y destinos, Madrid, CEPC, 1988.

Manzana Laguarda, R.: - Derechos y deberes de los Funcionarios Públicos. Tirant lo Blanch. Valencia, 1966. - La nueva Función Pública. Tirant lo Blanch. Valencia, 2013. 
Marina Jalvo, B.: El régimen disciplinario de los funcionarios públicos. Valladolid, 1999.

Martínez de Pisón Aparicio, I.: Del Estatuto de 1918 a la reforma de López Rodó: los coletazos del Spoil System en el Derecho Funcionarial Español. Anuario jurídico y económico escurialense. Real Centro Universitario Escorial-María Cristina. San Lorenzo del Escorial, 1992.

MaRTínez JimÉnEZ, J.E.: Las bases del sistema español de incompatibilidades de los funcionarios públicos. Documentación Administrativa $\mathrm{n}^{\circ}$ 195. Madrid, 1982

Martínez Marín, A.: Régimen jurídico de los funcionarios. TECNOS. Madrid, 2001. - MENDOZA OLIVÁN, V.: La ordenación de las incompatibilidades en la Ley Articulada de Funcionarios Civiles del Estado. Revista Documentación Administrativa $\mathrm{n}^{\circ} 77$. Madrid, 1964. MESEGUER YEBRA, J.: El régimen de las incompatibilidades del personal al servicio de las Administraciones Públicas. S.A. BOSCH. Barcelona, 2002.

Morán MARTín, Remedios "Los desgarros y los ritmos. Sobre los orígenes académicos de la doctrina constitucional en España" en $e S$ legal History Review n ${ }^{\circ}$ 7. 2009.

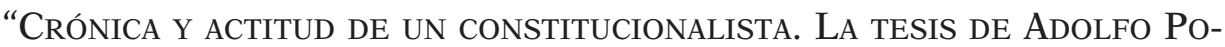
SADA SOBRE La TITULARIDAD DE LA SOBERANÍa" EN ESTUdios DE DEUSTO, 64.1, 2016.

Morán Martín, J., García Martín, J., Historia de la Administración en España: Mutaciones, sentido y Rupturas, Editorial Universitas S.A. Madrid, 2018,

MoRell OCAÑA, L.: Las reformas administrativas de Maura en VV.AA: Reformistas y reformas en la Administración española. INAP. Madrid, 2005. MORILLO-VELARDE PÉREZ, J.I.: - Las situaciones administrativas de los funcionarios en la Ley de Medidas para la Reforma de la Función Pública. Revista Española de Derecho Administrativo $\mathrm{n}^{\circ}$ 48. Civitas. Madrid, 1985. - A selección dos funcionarios públicos de 1808 a 1964. III Simposio de Historia da Administración Pública. Santiago de Compostela, 1996

MuÑoz LlinÁs, J. I.: - Los sistemas de carrera y movilidad administrativa en el modelo español de Función Pública: análisis y propuestas. Revista Parlamentaria de la Asamblea de Madrid, ${ }^{\circ} 27$. Madrid, 2012. - La carrera administrativa en los orígenes del constitucionalismo español: 1812-1918. Revista de Derecho UNED. Madrid, 2013. 
MuÑz Machado, S.: Sobre la burocracia de las Comunidades Autónomas. Revista de Documentación Administrativa, 182, abril-junio 1979. INAP. Madrid. NIGRO, F. A.: Administración de personal. Estudios Administrativos. Madrid, 1966

Nieto, A.: El desgobierno de lo público, Ariel, 2008.

Ortega Alvarez, L. (Director): Estatuto Básico del Empleado Público, La Ley, 2007.

Palomar Olmeda, A.: El sistema de carrera y su aplicación a los Cuerpos Superiores de la Administración, Dykinson, Madrid, 2002.

Palomar Olmeda, A., Sempere Navarro (Directores): Comentarios a la Ley 7/2007, de 12 de abril, del Estatuto Básico del Empleado Público, Aranzadi, 2007.

Parada Vázquez, R.: - Derecho del Empleo Público. Marcial Pons. Madrid, 2007. - La degeneración del modelo de Función Pública. Revista de Administración Pública, $n^{\circ}$ 150. Madrid. - Derecho Administrativo II: Organización y empleo público. Marcial Pons. Madrid, 1992.

PAREJo Alfonso, L.: Eficacia y Administración: tres estudios. INAP. Madrid, 1995.

PÉRez- Prendes, José Manuel, Historia del Derecho español, Madrid, Universidad Complutense, 2004, Vol. I

"El ascua orientada. Sobre la Teoría e las Cortes de Francisco Martínez Marina" en Escritos de historia constitucional de España, Madrid, Marcial Pons, 2017.

"Notas sobre el radicalismo constitucional de Agustín Argüelles" en Escritos.

"De metafísica constitucional. Ensayo de comentario al Dictamen de "reforma" en 1845 en Escritos.

"Álvaro Flórez. Estrada y la emancipación de América" en Joaquín Varela Suanzes- Carpegna (coord.), Álvaro Flórez Estrada (17661853). Política, economía y sociedad. Llanera (Asturias), Junta General del Principado, 2004.

Parrado DíEz, S.: Sistemas Administrativos Comparados. TECNOS. Madrid, 2002. PÉREZ MARCOS, R.M. y SÁNCHEZ GONZÁLEZ, M.D.: Introducción a la Historia de la Administración en España. UNED. Madrid, 2003. PIÑAR MAÑAS, J.L.: El nuevo sistema retributivo de los funcionarios públicos y su aplicación. RAP, $\mathrm{n}^{\circ} 111$. Madrid, 1986. 
Posada Herrera, José Lecciones de Administración (1843), Madrid, INAP, 1978.

Pro Ruiz, J. "Bravo Murillo: Política de orden en la España liberal”. Ed. Síntesis. Madrid, 2006.

Rivas Santiago, N.: Luis López Ballesteros: gran ministro de Fernando VII. Mediterráneo. Madrid.

Rodríguez Fernandez, A. (Dir.): Los recursos humanos en las Administraciones públicas. TECNOS. Madrid, 1995.

Romero Salmerón, M.: Función Pública: situaciones administrativas. Estudios de divulgación n ${ }^{\circ}$ 67. Granada, 1996.

SÁnchez Morón, M. (Director): Comentarios al Política, economía Ley del estatuto Básico del Empleado Público, Lex Nova, Valladolid, 2006.

Informe de la Comisión para el Estudio y Preparación del Estatuto Básico del Empleado Público, INAP, Madrid, 2005.

Sarmiento Larrauri, J. I.: - Estatuto O’Donnell. Revista Facultad del Derecho Universidad Complutense de Madrid no 94 . Madrid, 19992000. Pág.: 203-218. - Las Situaciones Administrativas de los funcionarios públicos. Revista vasca de Administración Pública no 19. Instituto Vasco de Estudios de Administración Pública. Guipúzcoa, 1987.

SARRIÓN Gualda, José, "Métodos de formación y técnicas de selección del funcionario público en nuestro siglo XIX, EN Revista Vasca de Administración pública 10, 1984

Solé TuRa, Jordi y AJA, Eliseo, Constituciones y períodos constituyentes en España (1808-1936) , Madrid, siglo XXI, 2009.

SUÁREz, F.: Documentos del reinado de Fernando VII. Luis López Ballesteros y su gestión al frente de la Real Hacienda (1823-1832). Vol. V. Ediciones de la Universidad de Navarra. Pamplona, 1970.

SuAy Rincón, J.: Potestad disciplinaria. En libro homenaje a Villar Palasí. Madrid, 1989.

Tomás Villarroya, Joaquín, "El Gobierno durante el reinado de Isabel II en 1812-92.

Toña Güenaga, F., Calonge Crespo, I., González De Heredia Maruri, C., Gorriti Bontigui, M. Pérez Barrio, A., Jiménez Asensio, R.: Informe "Estatuto Básico del Empleado Público y márgenes de configuración del legislador vasco para su desarrollo" 
Vallejo Pousada, R.: La reforma de la Hacienda de López Ballesteros y el origen de la regulación del delito fiscal en la España Contemporánea. Revista Anuario de Historia del Derecho Español. Tomo 67, Vol. II. Madrid, 1997. 
